\title{
E-LEARNING: APPROPRIATE E-MATERIALS FORMATTING FOR USERS HEALTH
}

\author{
Kristine Mackare \\ Liepaja University, Faculty of Science and Engineering, Latvia \\ Anita Jansone \\ Liepaja University, Faculty of Science and Engineering, Latvia
}

\begin{abstract}
E-learning has a direct relationship with public health as e-materials are making a huge amount of near workload for e-learners' eyes. As it is known, the huge near workload is one of the main reasons for the myopia development of nowadays population. The visual system can quickly become overloaded, especially by inappropriate e-material formatting. Based on theoretical research, incorrect formatting is used in most e-materials based on wrong recommendations. Recommendations and methodologies are not up-to-date for screen use. According to publications in the period of more than 20 years, near work and accommodation are the key factors for myopia development and progression. Appropriate formatting parameters of e-materials play an important role in reducing possible risk factors for myopia development. It could be achieved by using appropriate formatting parameters for e-learners. E-material font type must be perceptible and comprehensible from the screen, font size and line spacing must be appropriate for the reader based at least on its age and intellectual level, colour of background and text must help perception and reading process and could be different for each individual. All variables are important for individual and public health goals. New recommendations and automatization of the formatting process are developed to reach improvement.
\end{abstract}

Keywords: e-learning, e-materials, e-study, formatting app, myopia, public health.

\section{Introduction}

In the nowadays digital age, mostly everything is connected through digital devices, the Internet, social media, and apps. One smaller or bigger part of an everyday routine or its change same as parameter change of digital devices, programs, and apps, can make an impact on ours or others' life and wellbeing. Especially in the time of fast development and innovation of all life edges.

Public health involves different disciplines as engineering, education, computer science, medicine, sociology, and others (Detels et al., 2009). It is the base of the relationship between them and insight into different factors that affect societies' health, research, develop, and provides innovative solutions.

E-learning as a part of self-development and the modern public educational system has a direct relationship with public health as e-materials that in a different

(C) Rēzeknes Tehnologíiju akadēmija, 2020

http://dx.doi.org/10.17770/sie2020vol4.4889 
form are in use of knowledge providing, are making a huge amount of near workload for e-learners' eyes. As it is known, the huge near workload is one of the main reasons for the myopia development of nowadays population. Various types of near work have been suggested to promote the incidence and progression of myopia (Guan et al., 2019). The visual system can quickly become overloaded, especially by inappropriate e-material formatting. Based on theoretical research incorrect formatting is used in most e-materials based on wrong recommendations. Recommendations and methodologies are not up to date for screen use.

According to publications in the period of more than 20 years, near work and accommodation are the key factors for myopia development and progression (Muhamedagic et al., 2014).

\section{Literature review}

Despite all the advantages the mobile devices can also create problems such related to losing concentration during classes and diminishing classroom discussion (Maxwell, 2007; Murray, 2011).

Lots of digital device users have a sense of discomfort and vision problems after near work at screens (Kokab \& Khan, 2012). It is related to human visual perception (Ramamurthy \& Lakshminarayanan, 2015) and how people get and analyzed information. There are differences in perception from printed materials and digital displays (Seok \& DaCosta, 2016).

The prevalence of myopia was $18.1 \%$ (3607 of 19,934 students). Greater computer use $(\mathrm{P}<.001)$, smartphone use, television viewing, and after-school study, as well as less midday outdoor time, were also associated with greater myopia prevalence $(\mathrm{P}<.001)$. Myopia $\mathrm{VA} \leq 6 / 12$ and $\mathrm{SE} \leq-0.5 \mathrm{D}$ in at least one eye (Dirani, Crowston, \& Wong, 2018; Guan, et al. 2019).

To successfully participate in e-learning and e-studies, users need both excellent e-skills and well-designed e-learning materials: high-quality content, comfortable, easy-to-understand, and comprehensible text, suitable formatting parameters of e-materials (Mackare, Jansone, \& Zigunovs, 2018).

Current research represents a focus on content visualization, such as typographic aspects like font, font size, spacing, and colours. Formatting parameters regulate them. See figure 1 . It creates a more individual learning environment that is more comfortable for educational material perception from the screen (Mackare \& Jansone 2019b). 
SOCIETY. INTEGRATION. EDUCATION

Proceedings of the International Scientific Conference. Volume IV, May $22^{\text {th }}-23^{\text {th }}$, 2020. 508-515

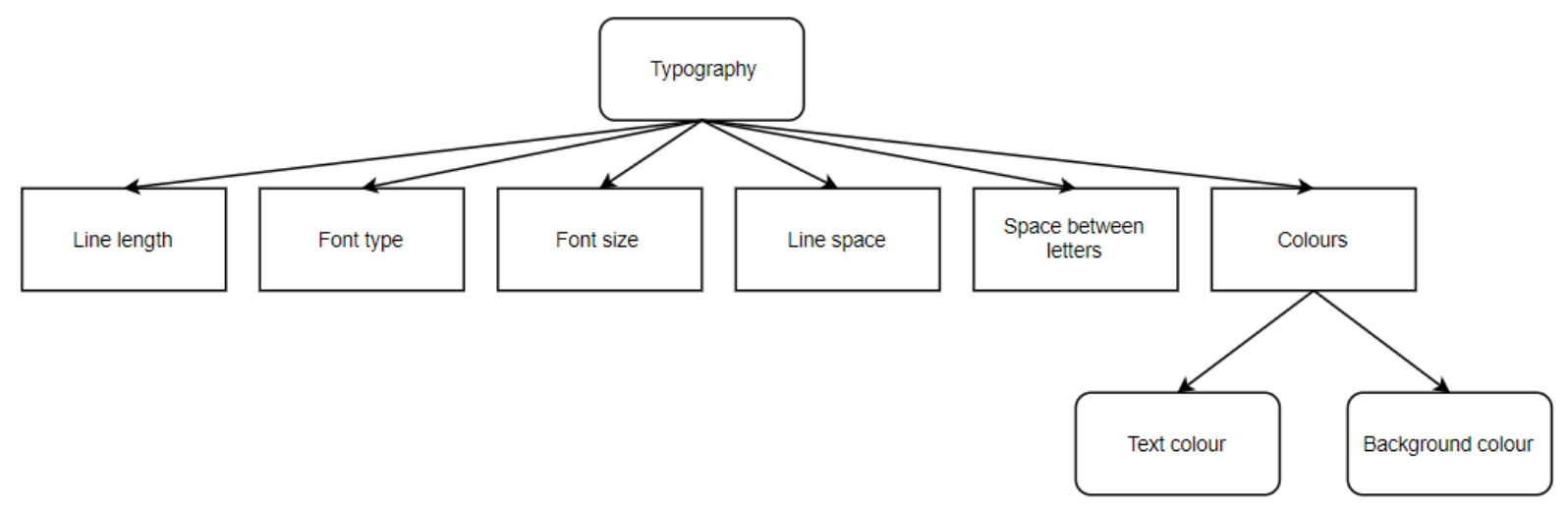

Figure 1 Content visualisation typographic aspects

Recommendations for e-material formatting guidelines (Table 1 ) of the most important typographic aspects were developed for the target group without reading difficulties and without any significant vision problems. A wider overview has presented at previous publication (Mackare \& Jansone, 2017a; Mackare \& Jansone, 2017b; Mackare \& Jansone, 2018; Mackare, Jansone, \& Zigunovs, 2018).

Table 1 Recommendations for guidelines

\begin{tabular}{|c|l|l|c|c|l|}
\hline \multirow{2}{*}{$\begin{array}{c}\text { Target group } \\
\text { by age }\end{array}$} & \multicolumn{5}{|c|}{ Formatting parameters } \\
\cline { 2 - 6 } & Font & $\begin{array}{c}\text { Body text } \\
\text { size }\end{array}$ & $\begin{array}{c}\text { Headings } \\
\text { size }\end{array}$ & $\begin{array}{c}\text { Line } \\
\text { spacing }\end{array}$ & $\begin{array}{c}\text { Background and text } \\
\text { colour }\end{array}$ \\
\hline $7-15$ & Arial & $12-18 \mathrm{pt}$ & $\geq 14-20 \mathrm{pt}$ & 1,15 & Black on white \\
\cline { 2 - 6 } & Verdana & & & & Dark grey on white \\
\cline { 2 - 6 } & TNR & & & 1,5 & Bhite on black \\
\hline $16-39$ & Arial & $\geq 14 \mathrm{pt}$ & $\geq 16 \mathrm{pt}$ & & Dark on white \\
\cline { 2 - 6 } & Verdana & & & & Dark green on white \\
\cline { 2 - 6 } & Georgia & & & & Black on white \\
\hline \multirow{2}{*}{$40+$} & Arial & $\geq 14-16 \mathrm{pt}$ & $\geq 16-18 \mathrm{pt}$ & & Dark green on white \\
\cline { 2 - 6 } & Verdana & & & & $\begin{array}{l}\text { Very dark grey on } \\
\text { white }\end{array}$ \\
\cline { 2 - 6 } & Georgia & & & & \\
\hline
\end{tabular}

Source: Mackare, Jansone, \& Zigunovs, 2018

Developed recommendations have been used for automatized e-material formatting app development. The wider overview has presented at previous publications (Mackare, Jansone, \& Zigunovs, 2018; Mackare \& Jansone, 2019a; Mackare \& Jansone, 2019b; Mackare, Jansone, \& Konarevs, 2019).

This have been up to date topic for last 20 years but there are not enough research. Is it really formatting change for screen reading to make any improvement in users' comfort or public health? 


\section{Methodology}

Methodology: Data record examining and short questioner of computer users.

Patient data records

Part 1: Used 879 patient observation record cards of authors-optometrists' patients' data records from 2017 from one of Latvia optic. But there are thoroughly analyzed 867 record cards as 12 were excluded by not full information content. Partly this data has been overviewed in the previous publication (Mackare \& Jansone, 2018).

Part 2: Used 1268 patient observation record cards of authors-optometrists' patients' data records from 2018 from one of Norwegian optics.

There are used only on research related data: gender, age, is it first time or repeated check, time between previous and current check, amount of refraction change, is new correction prescribed, is patient computer user, have patient complains about vision and what kind of complains have been found, and objective findings. All data records used according to personal data privacy and security rules.

Questioner contains eight questions - 6 with several answers possibilities as never, sometimes, often or not related, and 2 with yes/no answers. Response collected from 200 respondents-digital device users.

\section{Research results}

Patient data analysis:

From 867 record cards of Latvian patients' descriptive statistics shows, 552 patients were women and 315 patients - men, the age group from 12 to 82 . Data show, $99,8 \%$ of patients use a computer, and $31 \%$ of them come for a first vision check.

From 1268 record cards of Norwegian patients' descriptive statistics shows, patients' age group are from 4 to 98 . Data show, $100 \%$ of patients use a computer and/or other digital devices with screens.

Patient data record analysis:

The most common symptoms and complains of digital device users are combined in Table 2. Data of symptoms and complains mentioned by patients in records represents in percent from Latvia and Norway patients' records.

Almost all patients (99\%) mentioned complains about changes in vision (see worse at all distances or only at one), same as $97-98 \%$ of patients feel vision clearness change and can't see small letters or numbers at near or long distances. More than half of patients complain about: Problems with changing focus distance, discomfort at near work, reading or computer work, vision becomes 
SOCIETY. INTEGRATION. EDUCATION

Proceedings of the International Scientific Conference. Volume IV, May $22^{\text {th }}-23^{\text {th }}, 2020.508-515$

blurry and/or see double and eyes become red. About one half experience symptoms as a feeling of burning, itching, etc. eyes and feeling of dry eyes or feeling of sands in eyes. In most data are no significant differences between Latvian and Norwegian patients except a complaint as the feeling of tiredness in eyes or head.

Table 2 Symptoms mentioned in patients' anamneses

\begin{tabular}{|l|c|c|}
\hline \multirow{2}{*}{ Symptoms/ complains } & \multicolumn{2}{c|}{$\begin{array}{c}\text { Symptoms/complains } \\
\text { mentioned by patients, \% }\end{array}$} \\
\cline { 2 - 3 } & Latvia & Norway \\
\hline Feeling of dry eyes or feeling of sands in eyes & 51 & 47 \\
\hline Feeling of burning, itching, etc. & 52 & 53 \\
\hline Watery or "running” eyes & 21 & 17 \\
\hline Eyes become red & 57 & 62 \\
\hline pain or pressure-like feeling in eyes & 26 & 23 \\
\hline $\begin{array}{l}\text { Headaches (around eyes, in forehead, temples, or back of the } \\
\text { head) }\end{array}$ & 31 & 38 \\
\hline Feeling of tiredness in eyes or head & 64 & 33 \\
\hline Vision become blurry and/or see double & 56 & 59 \\
\hline $\begin{array}{l}\text { Feels vision clearness change / can't see small letters or numbers } \\
\text { at near or distance }\end{array}$ & 97 & 98 \\
\hline Problems with changing focus distance & 56 & 68 \\
\hline Changes in vision (see worse at all distances or only at one) & 99 & 99 \\
\hline Discomfort at near work, reading or computer work & 59 & 57 \\
\hline Eyes become sensitive to light & 2 & 3 \\
\hline
\end{tabular}

Patients are not only having complains or symptoms, but there are relevant findings on optometrist vision and eyes examination. The most common optometrist findings of digital device users are combined in Table 3. Data on optometrist findings represent in percent from Latvia and Norway patients' records.

Almost all patients (99\%) have changes in visual acuity. Same, about 97$98 \%$ of patients, have changes in refraction, and more than half are under myopization process. More than $3 / 4$ of patients in Latvia and about $84 \%$ of patients in Norway have been diagnosed with a Dry Eye Syndrome by findings of related changes under biomicroscopic observation. Most of this is low or extremely low tear line and conjunctival and/or limbal hyperaemia. In most data is no significant differences between Latvian and Norwegian patients. 
Table 3 Findings mentioned in patients' anamneses

\begin{tabular}{|r|c|c|}
\hline \multicolumn{1}{|c|}{ Findings } & \multicolumn{2}{|c|}{ Have changes, \% } \\
\cline { 2 - 3 } \multicolumn{1}{|c|}{ low or extremely low tear line } & Latvia & Norway \\
\hline $\begin{array}{r}\text { Dry Eye Syndrome related changes by biomicroscopic } \\
\text { observation: }\end{array}$ & 75 & 84 \\
\hline foamy tears & 65 & 73 \\
\hline viscous tears & 23 & 8 \\
\hline conjunctival wrinkles & 42 & 21 \\
\hline conjunctival staining & 11 & 37 \\
\hline MGD & 25 & 9 \\
\hline \multicolumn{1}{|c|}{ conjunctival and/or limbal hyperaemia } & 71 & 69 \\
\hline $\begin{array}{l}\text { Conjunctival and limbal hyperaemia without other dry } \\
\text { eye syndrome findings }\end{array}$ & 4 & 6 \\
\hline Accommodation problems & 11 & 13 \\
\hline Changes in visus & 99 & 99 \\
\hline Changes in refraction & 98 & 97 \\
\hline Myopization (Myopia progress, grow) & 58 & 67 \\
\hline
\end{tabular}

Almost all patients (computer users and non-users) had changes in refraction. It varies from $\pm 0,25 \mathrm{D}$ to $\pm 2,0 \mathrm{D}$. Internet users till 40 years had average $0,50 \mathrm{D}$ $(\mathrm{SE}=0,013, \mathrm{SD}=0,3)$ change in 6-24 months. Patients over 40 years had bigger change in same period - average $1,0 \mathrm{D}(\mathrm{SE}=0,025, \mathrm{SD}=0,47)$.

Questionnaire data are represented in table 4 and table 5. Data of respondents' answers represents in percent.

Table 4 Patient comfort of reading on screens

\begin{tabular}{|l|c|c|c|c|}
\hline \multicolumn{1}{|c|}{ Statement } & Never & Sometimes & Often & $\begin{array}{c}\text { Not } \\
\text { related* }\end{array}$ \\
\hline $\begin{array}{l}\text { Letters and numbers look too small for } \\
\text { comfortable reading on computer screen }\end{array}$ & $22 \%$ & $45 \%$ & $33 \%$ & - \\
\hline $\begin{array}{l}\text { Feel need to adjust reading distance (computer } \\
\text { screen) }\end{array}$ & $27 \%$ & $33 \%$ & $40 \%$ & - \\
\hline $\begin{array}{l}\text { Letters and numbers look too small for } \\
\text { comfortable reading on tablet screen }\end{array}$ & $25 \%$ & $23 \%$ & $12 \%$ & $40 \%$ \\
\hline Feel need to adjust reading distance (tablet screen) & $23 \%$ & $11 \%$ & $26 \%$ & $40 \%$ \\
\hline $\begin{array}{l}\text { Letters and numbers look too small for } \\
\text { comfortable reading on smartphone screen }\end{array}$ & $28 \%$ & $22 \%$ & $47 \%$ & $3 \%$ \\
\hline $\begin{array}{l}\text { Feel need to adjust reading distance (smartphone } \\
\text { screen) }\end{array}$ & $19 \%$ & $23 \%$ & $55 \%$ & $3 \%$ \\
\hline
\end{tabular}

*not related = are not using this kind of device ever or for reading tasks 
Questionnaire data represent in table 4 show what $40 \%$ of respondents don't have or are not using tablets for reading tasks, same as 3\% of respondents don't have or are not using a smartphone for reading tasks. Almost $80 \%$ admit that letters and numbers look too small for comfortable reading on a computer screen, and $73 \%$ feel a need to adjust the reading distance of a computer screen. More than half of tablet users admit that letters and numbers look too small for comfortable reading, and 2/3 feel a need to adjust the reading distance of the tablet screen. About $70 \%$ of smartphone users admit that letters and numbers look too small for comfortable reading, and almost $80 \%$ feel a need to adjust the reading distance between eyes and smartphone screens.

Table 5 Need of text increase

\begin{tabular}{|l|c|c|}
\hline \multicolumn{1}{|c|}{ Statement } & Yes & No \\
\hline Have you tried to increase a size of letters and numbers you need to read? & $49 \%$ & $51 \%$ \\
\hline Did it help? & $80 \%$ & $20 \%$ \\
\hline
\end{tabular}

Almost half of respondents have tried to increase a size of reading material letters and numbers, and $80 \%$ of them experience increase of readability comfort.

\section{Conclusions}

Current research and patient data record analysis from Latvia and Norway show screen reading effect on readers vision.

Most digital devices users are experiencing different symptoms and having complains during and after near work, especially related to screen use. A significant part of them are not only having complains, but there have been relevant findings on optometrist vision and eyes examination. A significant part of digital device users has myopization signs based on refraction changes.

Most of the computers, tablets, and smartphone users have experienced what letters and numbers that must be read seems too small and unreadable on screen as well as experienced a need to adjust the reading distance. Almost part has tried to increase a size reading material, and $80 \%$ of them experience an increase of readability comfort.

E-material font type must be perceptible and comprehensible from the screen, font size and line spacing must be appropriate for the reader based at least on its age and intellectual level, colour of background and text must help perception and reading process and could be different for each individual.

All variables are important for individual and public health goals. Appropriate formatting parameters of e-materials play an important role in reducing possible risk factors for myopia development. 
New recommendations and automatization of the formatting process are in development to reach improvement.

\section{References}

Detels, R., Beaglehole, R., Lansang, M.A., \& Gulliford, M. (2009). Oxford Textbook of Public Health (5 ed.), Oxford University Press.

Dirani, M., Crowston, J.G., \& Wong, T.Y. (2018). From reading books to increased smart device screen time, Br J Ophthalmol;0:1-2. DOI:10.1136/bjophthalmol-2018-313295

Guan, H., Yu, N.N., Wang, H., Boswell, M., Shi, Y., Rozelle, S., \& Congdon, N. (2019). Impact of various types of near work and time spent outdoors at different times of day on visual acuity and refractive error among Chinese school-going children, PLoS One.; 14(4), e0215827. DOI: 10.1371/journal.pone.0215827

Kokab, S., \& Khan, M.I. (2012). Computer vision syndrome: a short review, Journal of Evolution of Medical and Dental Sciences, 1(6), 1223-1226. DOI: 10.14260/jemds/199

Mackare, K., \& Jansone, A. (2017a). Research of guidelines for designing e-study materials ETR17, Proceedings of the 11th International Scientific and Practical Conference Environment, Technology, Resources, June 15-17, Rezekne, Latvia, Volume 2, 90-96.

Mackare, K., \& Jansone, A. (2017b). Recommended formatting parameters for e-study materials, Conference proceeding book of the 3rd International Conference on Lifelong Education and Leadership for All; SEP 12-14; Porto, Portugal, 514-522.

Mackare, K., \& Jansone, A. (2018). Recommended formatting parameters for e-study materials IJLEL Journal, 4(1), 8-14.

Mackare, K., Jansone, A., \& Zigunovs, M. (2018). E-material creating and formatting application, Book series: Advances in Intelligent Systems and Computing 876, Human Systems Engineering and Design: Proceedings of the 1st International Conference on Human Systems Engineering and Design (IHSED2018): Future Trends and Applications, October 25-27, 2018, Reims, France, 135-140.

Mackare, K., \& Jansone, A. (2019a). The concept for e-material creating and formatting application prototype, PEN, Periodicals of Engineering and Natural Sciences, 7(1), 197-204.

Mackare, K., \& Jansone, A. (2019b). Personalized learning: effective e-material formatting for users without disability or specific limitation, Educational Alternatives, 17, 194-206.

Mackare, K., Jansone, A., \& Konarevs, I. (2019). The prototype version for e-material creating and formatting application, BJMC journal, 7(3), 383-392

Maxwell, N. (2007). From Facebook to Folsom Prison Blues: How Banning Laptops in the Classroom Made Me a Better Law School Teacher, Richmond Journal of Law \& Technology, $X I V(2)$.

Muhamedagic, L., Muhamedagic, B., Halilovic, E.A., Halimic, J.A., Stankovic, A., \& Muracevic, B. (2014). Relation Between Near Work and Myopia Progression in Student Population, Mater Sociomed. Apr; 26(2), 100-103. DOI: 10.5455/msm.2014.26.100-103

Murray, K.E. (2011). Let Them Use Laptops: Debunking the Assumptions Underlying the Debate Over Laptops in the Classroom. Oklahoma City University Law Review, 36.

Ramamurthy, M., \& Lakshminarayanan, V. (2015). Human Vision and Perception, Handbook of Advanced Lighting Technology, Springer.

Seok, S., \& DaCosta, B. (2016). Perceptions and Preferences of Digital and Printed Text and Their Role in Predicting Digital Literacy, Asian Social Science, 12(5), 14-23. 